Lexis Vol. XLV (2) 2021: 891-916

\title{
Adolescentes en la ciudad: rebeldía y conformismo en la narrativa peruana moderna*
}

\author{
Alejandro Susti \\ https://orcid.org/0000-0003-4489-8273 \\ Universidad de Lima \\ asusti@ulima.edu.pe
}

\section{RESUMEN}

Este trabajo examina dos textos narrativos editados en el Perú durante la década de los años sesenta: Los inocentes. Relatos de collera ([1961] 2011) de Oswaldo Reynoso (1932-2016) y Los cachorros (1967) de Mario Vargas Llosa. El análisis se centra en la construcción de las identidades de los sujetos adolescentes que los protagonizan, tomando en cuenta una serie de factores (clase, generación, género, territorialización, lenguaje, entre otros) como parte de la emergencia de las llamadas "culturas juveniles" en las sociedades occidentales a partir de la década de los cincuenta. Se reconocen, asimismo, diferencias entre estas narrativas en la representación de esas culturas, en particular, con respecto a la relación que los sujetos adolescentes establecen con la cultura hegemónica.

Palabras clave: narrativa peruana del siglo XX, ciudad y literatura, adolescencia y literatura, culturas juveniles

Esta investigación ha sido realizada con el apoyo del Instituto de Investigación Científica (IDIC) de la Universidad de Lima.

https://doi.org/10.18800/lexis.202102.012 
Adolescents in The City: Rebellion and Inconformism in Peruvian Modern Narrative

\begin{abstract}
This article examines two narrative texts published in Peru during the sixties: Los inocentes. Relatos de collera ([1961] 2011) by Oswaldo Reynoso (1932-2016), and Los cachorros (1967) by Mario Vargas Llosa. The analysis focuses on the construction of identities among the adolescent subjects who star in them, considering elements such as social class, generation, gender, territory, language and others, as part of the emergence of the so-called "youth cultures" in western societies since the fifties. In addition, it recognizes the differences between both narratives in terms of the representation of youth cultures, particularly with respect to the relationship that adolescent subjects establish with hegemonic culture.

Keywords: Peruvian narrative of the 20th century, city and literature, adolescence and literature, youth cultures
\end{abstract}

La analogía “adolescencia-ciudad” resulta útil para hacer referencia a la fundación de un imaginario en la narrativa peruana de la generación del cincuenta en que el personaje adolescente ocupa un lugar protagónico ${ }^{1}$, así como a la concepción de la urbe como un organismo que, a la manera del joven adolescente, se encontraba en pleno proceso de expansión como producto de las transformaciones operadas desde la llegada a Lima de las primeras olas migratorias de mediados de la década de los años cuarenta. Los relatos incluidos en Los inocentes. Relatos de collera ([1961] 2011) de Oswaldo Reynoso (1932-2016) y la novela corta Los cachorros (1967) de Mario Vargas Llosa serán analizados a la luz del impacto producido por la emergencia de nuevas culturas juveniles en las sociedades occidentales tras la segunda guerra mundial, caracterizadas "por su precaria integración en la cultura hegemónica” (Feixa 1999: 85). Mi acercamiento presta atención a los factores y materiales que contribuyen

\footnotetext{
1 El adolescente, por ejemplo, se hace presente en los cuentos de Sebastián Salazar Bondy y Julio Ramón Ribeyro, así como en la novela Crónica de San Gabriel ([1960] 2001) de este último y en No una, sino muchas muertes (1957) de Enrique Congrains Martín.
} 
a la construcción de esas culturas y las identidades de los personajes adolescentes que protagonizan estas ficciones. Este acercamiento, sin embargo, no supone el hecho de que el surgimiento de esas culturas se realiza de manera análoga en países cuyas realidades distan mucho de haber alcanzado los niveles de desarrollo preconizados en el mundo occidental. Si como señala Roszak (1981: 41), en Estados Unidos, a fines de los años sesenta, "los adolescentes [de la clase media] controlan una formidable cantidad de dinero y tienen mucho tiempo libre, de suerte que, inevitablemente, se han dado cuenta del importante mercado que forman"2, esa situación es diametralmente opuesta en el caso de los protagonistas de los relatos de Reynoso, por ejemplo, a quienes se les niega toda posibilidad de integrarse a una sociedad en la que el consumo y la educación parecen ser las únicas credenciales para formar parte de ella y que, al no poder alcanzarlas, deben resignarse a formar parte de una subclase de ciudadanos comparable con lo que Marx reconocía como el lumpenproletariat.

\section{LA CONSTRUCCIÓN DE LAS IDENTIDADES JUVENILES}

Según Feixa (1999: 61), "las diversas formas de contestación y disidencia juveniles, los cambios en sus formas de vida y valores pueden ser interpretados como uno de los índices privilegiados de las «crisis de autoridad»". La crisis referida por el antropólogo se origina a partir del momento en que el sujeto adolescente descubre su inadecuación ante la racionalidad y el utilitarismo que rigen el tejido de la sociedad, así como el escaso control que tiene sobre la mayor parte de los aspectos decisivos en su vida y el sometimiento a la tutela (más o menos explícita) de espacios institucionales como la escuela, el trabajo y la familia. La cultura hegemónica representada por esas instituciones concibe a ese sujeto como "incompleto", es decir, incapaz aún de asumir las responsabilidades, compromisos y retos que supone la vida adulta, a la vez que una metáfora de lo transitorio; por ello,

\footnotetext{
2 Para Roszak, otro factor determinante de este fenómeno fue la significativa expansión de la enseñanza superior (1981: 42).
} 
sobre el adolescente han de ejercerse los mecanismos que posibiliten su conducción y adecuación al sistema productivo de la sociedad.

A pesar de estas características generales, las emergentes culturas juveniles conformadas por los adolescentes no son homogéneas, es decir, surgen condicionadas por diversos factores y materiales con los que construyen su identidad, ya sea para adoptar la cultura hegemónica o rebelarse ante ella. Entre estos se consideran, en primer lugar, aquellos de carácter social como la extracción de clase, la generación, el género y el territorio (Feixa 1999: 87). En el primero, por ejemplo, se diferencian las “culturas juveniles obreras” de las provenientes de la clase media y, en ambos casos, los adolescentes pueden adoptar soluciones adaptativas o disidentes; en el segundo, dada la transitoriedad que gobierna la vida del adolescente, las experiencias compartidas que perduran en el tiempo adquieren relevancia y se traducen en un horizonte común de referentes como acontecimientos, espacios determinados, entre otros elementos; en lo que atañe al género, las culturas juveniles se configuran históricamente como "fenómenos exclusivamente masculinos" en la medida en que "la reclusión femenina en el espacio doméstico las ha alejado de la calle o de los locales de ocio, espacios privilegiados de las culturas juveniles" (1999: 90). El cuarto factor, el territorio, reviste particular interés en este trabajo en la medida en que se relaciona con la resemantización de determinados espacios/zonas de la ciudad. En tal sentido, la memoria colectiva de cada generación evoca ciertos lugares físicos, así como redescubre territorios urbanos olvidados o marginales y asigna nuevos significados a zonas como plazas, calles y otras. Existen, por otra parte, factores de un segundo orden vinculados con las imágenes culturales, "entendidas como el conjunto de atributos ideológicos y simbólicos asignados y/o apropiados por los jóvenes”: así, “las culturas juveniles se traducen en estilos más o menos visibles, que integran elementos materiales e inmateriales heterogéneos, provenientes de la moda, la música, el lenguaje, las prácticas culturales y las actividades focales" (1999: 87-88). Entre estos últimos, los medios de comunicación, así como la cultura de masas propagada por estos, juegan un papel fundamental. 


\section{REBELDía Y DELINCUENCIA EN LOS INOCENTES}

Desde su publicación, Los inocentes. Relatos de collera despertó una ola de escándalo por la descarnada visión que ofrecían sus cinco relatos acerca de las condiciones de vida de un grupo de adolescentes, una collera, marginados por la sociedad y signados por la rebeldía y el rechazo a las normas de ciertas instituciones - la escuela, el trabajo, el sistema productivo e, incluso, el ámbito político-, así como a la cultura parental representada por los padres e individuos inmersos en la interacción cotidiana, es decir, miembros de otras generaciones dedicados a ocupaciones u oficios tales como profesores e inspectores de colegio, propietarios de establecimientos o simples trabajadores. En la medida en que estos jóvenes adoptan comportamientos, valores, prácticas y rituales diferentes a los de los adultos y desarrollan un lenguaje verbal y estilo que incluye entre otros aspectos un modo de vestir y un determinado lenguaje corporal, los miembros de la collera de los relatos de Reynoso configuran una suerte de microcultura asociada al concepto de la banda propuesto por Feixa:

[...] a banda sería una forma de microcultura emergente en sectores urbano-populares. Evitando el uso tradicional, asociado a determinadas actividades marginales, el concepto haría referencia a los grupos informales localizados de jóvenes de las clases subalternas, que utilizan el espacio urbano para construir su identidad social $[\ldots]$ (p. 87).

El término "collera”, empleado por el narrador, a diferencia de "pandilla”, se refiere a un grupo de jóvenes que definen su territorio cerca de la casa que habitan — generalmente, el vecindario-y tiene un sentido transitorio. La palabra "pandilla", en cambio, designa a un grupo que puede articular "colleras", pero que se define principalmente por la necesidad de conquista de un territorio (Güich y Susti 2007: 133). La diferencia terminológica, sin embargo, no relativiza el papel que desempeñan estos grupos en la construcción de la identidad de los adolescentes: 
La pandilla de varones interviene crucialmente en el período de la adolescencia en el que el muchacho, aunque ya informado durante la niñez de lo que es propio o impropio de un varón, se siente inseguro de su capacidad de convertirse en un auténtico varón, ya que tiene que romper con los hábitos de la niñez, no sólo porque ya no es un niño, sino porque todas las connotaciones de la niñez son oficialmente femeninas. El grupo de iguales, la pandilla, tendrá una importancia decisiva para él, precisamente porque su credibilidad es mayor que la de la familia y la escuela [...]. [La pandilla de amigos] le suministra una información aparentemente no jerárquica sobre cómo comportarse como un hombre y su utilidad parece tanto mayor al sujeto cuanto que la conciencia de un cambio social acelerado hace percibir al padre y aun a los varones adultos como anticuados (Marqués 1997: 25).

Los actos y conductas de los integrantes de la collera están férreamente regulados por un código que estipula "cómo comportarse como un hombre"; para ellos, la masculinidad se define como “[...] ser valiente, pendejo. [...] saber fumar, chupar, jugar, robar, faltar al colegio, sacar plata a maricones y acostarse con putas" (p. 14). El territorio en el que este opera, como se verá más adelante, es el de la calle y los espacios de ocio. Asimismo, construyen sus identidades a partir de la extracción de clase, la generación, el género y el territorio, así como las imágenes culturales. En primer lugar, habitan en el distrito de La Victoria, fundado a principios de la década de los años veinte del siglo XX como barrio obrero, ubicado en lo que entonces era parte de la periferia de la ciudad. Aun cuando en los relatos se hace breves alusiones a la ocupación de los padres ${ }^{3}$, la intrascendencia de su influencia en las vidas de los adolescentes es evidente. La disfuncionalidad de las familias de la mayoría de los personajes es otro factor determinante en la confrontación que adoptan frente a la cultura hegemónica, así como la cultura parental;

3 El padre de "Cara de Ángel”, protagonista del primer cuento, aparece me ncionado en un breve pasaje, del cual puede deducirse que fue un dirigente obrero que murió aparentemente por "meterse en política" (p. 17); el de "Colorete”, en cambio, es “cabrón”, término utilizado por el narrador para referirse a su condición de proxeneta (p. 16); finalmente, el de “El Príncipe” es dueño de un taller de mecánica de automóviles (p. 39). 
asimismo, la mayoría de ellos estudia en una Unidad Escolar ${ }^{4}$, cuyas figuras de autoridad son representadas desfavorablemente. Así, desde la perspectiva de clase y generación, los protagonistas se configuran como sujetos que se rebelan a la imposición de las normas que rigen la vida de los adultos.

En lo que respecta al género y, en particular, a la asignación de los atributos masculinos que el orden social exige, las relaciones de los adolescentes con las mujeres reproducen las formas de la dominación masculina, en el sentido formulado por Bourdieu (1998):

La virilidad, incluso en su aspecto ético, es decir, en cuanto que esencia del vir, virtus, pundonor (nif), principio de la conservación y del aumento del honor, sigue siendo indisociable, por lo menos tácitamente, de la virilidad física, a través especialmente de las demostraciones de fuerza sexual [...] que se esperan del hombre que es verdaderamente hombre (pp. 12-13).

Un ejemplo de ello se presenta en el relato "Cara de Ángel”, cuyo protagonista es un adolescente de apariencia andrógina:

Tengo el cabello crecido: mucho mejor. Cara de Ángel sí. Nunca: María Bonita. Ni mucho menos: María Félix. Que no se les vuelva a ocurrir llamarme así; porque les saco la mierda. No tengo cara de muchachita. Mi cara es de hombre. En mi rostro ya se vislumbra una pelusilla un poco dorada que, de aquí, a tres meses, será barba tupida y, entonces, usaré gillete. Si los muchachos del billar supieran lo que hice con Gilda, la hermana de Corsario, nunca volverían a llamarme María Bonita (p. 12).

Como señala Bourdieu, el "mundo social construye el cuerpo como realidad sexuada y como depositario de principios de visión y de división sexuantes" (1998: 11). Es en el cuerpo en donde se “construye la diferencia entre los sexos biológicos de acuerdo con los principios de una visión mítica del mundo arraigada en la rela-

\footnotetext{
4 Las unidades escolares fueron creadas en todo el país como parte de una reforma educativa llevada a cabo durante el gobierno del presidente Manuel A. Odría (1948-1956), como respuesta a la falta de infraestructura educativa capaz de satisfacer la demanda de una educación pública gratuita.
} 
ción arbitraria de dominación de los hombres sobre las mujeres" (1998: 11). La obsesión del personaje por una apariencia física que exprese su virilidad se traduce, además, en la necesidad de tener su primera relación sexual y vencer así el temor a no responder a las exigencias de un orden en que lo masculino se define por el dominio y la posesión de la mujer. La imagen del cuerpo sexuado masculino, incluso, está presente a través de la voz de la madre que repercute en la mente del protagonista: " "Así me gusta: bajo el sol, triste, y con las manos en los bolsillos. (Sólo los viciosos tienen esa costumbre). $¡ A l$ diablo con la vieja! Con las manos en los bolsillos. Porque quiero. Porque me da la gana»" (p. 11, las cursivas son mías). La afirmación de la virilidad y el aumento del honor, sin embargo, aparecen matizadas por el temor al cuerpo femenino. Si por un lado la mayoría de los personajes se abocan a la acentuación de sus atributos masculinos, ello también comporta el miedo a no satisfacer las exigencias localizadas en el cuerpo sexuado femenino; es decir, el fracaso en la relación con el sexo opuesto implica una feminización del sujeto masculino. No resulta casual, por ejemplo, que los dos personajes que compiten por el liderazgo de la collera -El Príncipe y Colorete- fracasen en sus relaciones con las muchachas de las cuales están enamorados:

Rapidito me fui a casa de Alicia. Silbé. Salió. Y estaba bien rica: ojerosa y con olor a cama sucia que arrechaba. La invité al cine. Me dijo que su mamá no la dejaba salir y que, además, tenía dolor de cabeza. Siempre lo mismo conmigo. Con Carambola es diferente. Para Carambola no hay dolor de cabeza. Para Carambola, su mamá la deja salir hasta de noche (p. 40).

Juanita. Juanita. Cuando te veo sufro. Cuando no, también. No sé qué hacer [...]. Las muchachas arregladas y bonitas que van a los tonos me dan miedo. Meten miedo. Imposible hablarles: tembladera y tartamudeo. Y si miran como diciéndome: ¿Por qué no me sacas a bailar? Tiemblo y me escondo. Mi campo es la calle. La Collera...Ahí soy atrevido. En la calle soy el capazote Colorete. Pero en los tonos me achico. Soy un cobarde (p. 52). 
En ambos casos se trata de reflexiones que deben permanecer ocultas ante los demás miembros de la collera, pues ello les merecería perder el liderazgo de la misma. Asimismo, ambos ignoran que la razón de ese rechazo es su extracción de clase: a pesar de pertenecer al mismo núcleo social, las muchachas ya tienen interiorizada la importancia de entregarse solo a aquellos muchachos que puedan ofrecerles un ascenso en la escala social. Tanto Colorete como El Príncipe están involucrados en actividades delictivas condenadas por el orden social: el primero "no sólo roba, sino hasta se vive, públicamente, con un maricón, que dicen que es doctor", afirma Cara de Ángel; el segundo ha sido capturado por la policía después de robar más de cinco mil soles y un auto. En ambos casos, el territorio en el que estos personajes se desarrollan y ejercen su autonomía, así como construyen su identidad social, es el de la calle - plazas, parques, la quinta del vecindario- o el ocio - el billar "La Estrella" o la cantina del japonés- ${ }^{5}$. Esta estricta semantización espacial opera como un umbral que limita la posibilidad de agencia de los sujetos adolescentes; es decir, una vez transpuestos los límites del espacio público, pierden las prerrogativas que han logrado capitalizar en base a sus atributos masculinos — virilidad, valentía, arrojo, rebeldía, entre otros- Por ello, no resulta extraño que en sus relaciones con las muchachas carezcan de las herramientas que podrían permitirles tener acceso y dominio de la esfera privada asignada por el orden social a las mujeres (Feixa 1999: 90) ${ }^{6}$. Ello explicaría, por ejemplo, la vulnerabilidad de Colorete al asistir a la fiesta de cumpleaños de Juanita en casa de esta última —aparte de su desconocimiento de las verdaderas intenciones de la adolescente ${ }^{7}$ - o la compensación que busca El Príncipe en Dora - una

\footnotetext{
El propio Colorete afirma en el relato: "Mi campo es la calle. La Collera...Ahí soy atrevido. En la calle soy el capazote Colorete. Pero en los tonos me achico. Soy un cobarde” (p. 52).

6 Esta estricta territorialización del espacio, sin embargo, no impide la posibilidad de sociabilización entre las propias mujeres, como señala Feixa (1999: 90).

7 Al final del cuento, Juanita hace evidentes esas intenciones al negarse a recibir el obsequio que Colorete le ofrece — un prendedor de plata- y continuar bailando con Javier Montero, "estudiante de derecho" (p. 55).
} 
prostituta mayor que trabaja en un burdel, quien sí parece estar enamorada de él一, una vez que ha sido rechazado por Alicia.

Esta territorialización también se expresa en el cuento "Carambola”, personaje que sí es aceptado por Alicia, quien se acerca a Choro Plantado - un maleante que frecuenta el billar del vecindario y que estuvo en la cárcel después de haber asesinado a su esposa- en busca de consejo antes de tener su primera relación sexual con ella:

-Usted que es corrido sabe que del plan de paleteo y chupete hay que pasar a otra cosa, no no puede quedarse en el plan de cochineo. México no es lo mismo, allí falta cariño, no sé... Pero para eso está la gila de uno. Y ya no me contengo, don Mario, y la chelfa está que quiere. Mañana domingo, o sea hoy, mis teclos se van a Chosica, no voy con ellos: les he dicho que tengo que estudiar para los exámenes. Voy a estar solo en mi hueco y he quedado con la gila para acostarnos en mi cama: vamos a estar solititísimos (p. 48).

Compartir un espacio privado con Alicia le abre al personaje la posibilidad de la relación sexual y la consolidación del afecto; Carambola, asimismo, expresa la ansiedad que provoca en él la trascendencia del encuentro, para lo cual se aproxima a una figura a quien admiran los miembros de la collera: paradójicamente, Choro Plantado cumple el rol de los padres del adolescente, lo cual demuestra la poca comunicación existente entre estos. Como ocurre en los casos de El Príncipe y Colorete, Carambola hace evidente su total desconocimiento de las verdaderas intenciones de la muchacha - y de las mujeres, en general—, como hace explícito el soliloquio final de Choro Plantado al separarse del adolescente: "Y mientras caminaba dijo, despacio, hablando consigo mismo: “ "Casi todas las chelfas son iguales. ¡Pobre Carambola! Si supiera que su tal Alicia es más puta que una gallina. Todas las gilas son igualitas. ¡Pobre Carambola!»” (p. 50). La constatación de la falsedad de Alicia, una vez más, refuerza la visión androcéntrica que coloca a la mujer como objeto de deseo de los personajes masculinos y que, además, victimiza a aquellos que carecen un conocimiento de las relaciones entre sexos. De este modo, la mujer es representada como un sujeto 
que manipula a los hombres para su propio beneficio - en este caso, el ascenso social- $-\mathrm{y}$ dispone de ellos para su placer, todo lo cual hace justificable la necesidad de dominarla y poseerla sexualmente.

En relación con las imágenes culturales, los relatos proporcionan múltiples ejemplos, como sucede en el dedicado a Cara de Ángel:

«Esa camisa roja que está en la vitrina es bonita, pero cara. Es marca B.V.D. Todas las vitrinas deberían tener espejos. [...] Con esa camisa mi rostro estaría más pálido. Me compraría un pantalón negro. Me compraría gafas oscuras. Tendría pinta de trasnochador "dispuesto a llegar hasta las últimas consecuencias de una vida intensa”, como dice Choro Plantado, el borracho de mi cuadra. Y mis diecisiete años, a lo mejor, se transforman en veinte $[\ldots]$ (p. 12).

La escena puede interpretarse como un ejemplo de la homogenización del gusto y presión que ejerce la sociedad de consumo en los adolescentes y revela lo que Marx describe como el "fetichismo de la mercancía", que convierte a los bienes de consumo en proyecciones de los deseos de los consumidores independientemente de las relaciones sociales que hacen posible su producción. Sintomáticamente, Cara de Ángel construye una imagen fantasmal de sí mismo ante la vitrina que encarna su marginalidad como sujeto de consumo en una sociedad materialista. De allí que no resulta casual la aparición en ese mismo pasaje de quien podría facilitarle la materialización de sus deseos: "Ahorititita, le saco la mierda a ese viejo que simula ver la vitrina cuando en realidad me come con los ojos. Está mira que te mira que te mira. Pensará: camisa roja y pichón en cama” (p. 12). A diferencia de Colorete, quien acepta prostituirse con un doctor para obtener ingresos, Cara de Ángel rechaza esa posibilidad. La presencia del homosexual, encarnación de un sujeto masculino feminizado, provoca en él repulsión —aun cuando más adelante reconozca haber dudado por un instante en aceptar el ofrecimiento- ${ }^{8}$.

La preferencia de Cara de Ángel por la camisa de color rojo y el pantalón negro es también una marca estética a través de la cual se

\footnotetext{
8 “[...] esta noche voy a México y no tendré miedo y el viejo si insiste un poco más casi me lleva da asco con viejo pero la camisa roja bonita [...]” (pp. 17-18)
} 
diferencian los miembros de la collera del gusto de los adultos. En otros pasajes el narrador enfatiza esa predilección por los colores intensos en la vestimenta de los adolescentes: "Atraviesan la calle y se dirigen a la parte más tupida y oculta del Parque de la Reserva. (Pantalones negros, azules, celestes; camisas rojas, negras, amarillas se estremecen delirantes entre ramas verdes)" (p. 19); “El asfalto brilla negro y el jebe de los zapatos amarillos resbala en el cemento" (p. 29). Este intenso cromatismo da cuenta de la necesidad de los adolescentes de diferenciarse de la monotonía y grisura del mundo que los rodea: en medio del paisaje urbano indiferenciado, intentan imponer un estilo y una estética visual a pesar de las carencias que la sociedad impone sobre ellos.

Otro elemento vinculado con las imágenes culturales se relaciona con el lenguaje verbal. Los personajes comparten un repertorio de formas de expresión oral que involucran palabras, giros, frases hechas, etc. provenientes de sociolectos anteriores, de la jerga del hampa y de una creatividad lingüística que los diferencia del lenguaje de los adultos, las muchachas y los medios de comunicación. Así, expresiones que aluden a estados de ánimo, reacciones emocionales, partes del cuerpo, órganos sexuales, acciones, el dinero, instrumentos de uso cotidiano y muchas más integran un vocabulario de casi un centenar de términos ${ }^{9}$. Este repertorio lo utilizan para comunicarse entre sí e, incluso, es apropiado por el narrador heterodiegético para hacer explícito el pensamiento de los personajes. Inserto en el espectro de posibilidades lingüísticas que se realizan en la narración, el lenguaje de los adolescentes se caracteriza por su estridencia, inventiva y expresividad, como se comprueba en los breves relatos que describen sus "hazañas":

-De pronto, sin que nadies se diera cuenta este negro émierda comenzó a tocar gemelas. [...] El pelo lo tenía, al principio planchado y brillante; pero, ¡carajo! La pasa no esconde, compadre. Tremenda bulla que se armó en el barrio. Todos los de la Quinta pidieron al

9 La editorial Estruendomudo, por ejemplo, al conmemorarse los cincuenta años de la publicación del volumen, incluyó un "Vocabulario básico" como apéndice. 
japonés que pusiera Canal 13, para ver a este Natkinkón en jodas. Salieron en la pantalla «Las Candelitas», famoso dúo cubano, y al fondo, como una mancha, en medio de más de diez músicos, estaba este negro hediondo, moviéndose como una puta. De un momento a otro, avanzó y en toda la pantalla apareció tremenda cara de mono y comenzó a saludar. Pucha, si es bruto mi cuñao. Lo sacaron a patada limpia (p. 32).

En medio de la complicidad del resto de la collera, el relato destaca la capacidad del protagonista Natkinkón para burlar los códigos sociales. Poco importa si los eventos se desarrollaron en la forma en que los describe el Rosquita — narrador de la historia-, lo fundamental es crear a través del lenguaje un relato ágil y ameno que en pocas palabras produzca empatía con el auditorio. El lenguaje es, pues, un instrumento de consolidación de los lazos entre los miembros de la collera y su uso implica verbalizar y visibilizar algunos de los atributos con los que se construye la identidad de los adolescentes.

La música a lo largo de los relatos de Los inocentes es también otro factor a considerar. En los espacios de ocio en los que se reúne la collera están presentes las radiolas cuya música acompaña los estados de ánimo de los adolescentes. El ejemplo más ilustrativo aparece en el cuento "Colorete" cuando la letra y música de la guaracha "Marina" hace recordar al protagonista a Juanita, una muchacha del barrio de la cual está enamorado, y lo sumerge en una melancolía profunda: “[...] a mí, la guaracha me pone triste. Pero triste de triste. Triste de no sé qué. Parece que las maracas revolvieran en el fondo de mi pecho una culebra ardiente” (p. 52). La música ayuda a canalizar los afectos y emociones del personaje, quien sabe, además, que se encuentra en una situación vulnerable, pues el enamoramiento - y, en general, el ámbito de lo afectivoimplica una feminización de acuerdo con la visión que comparte con los demás integrantes de la collera ${ }^{10}$.

10 Es también significativo el hecho de que el personaje haga alusión a "una culebra ardiente" que se revuelve en su pecho, símbolo fálico, pero también alusión al pecado original. 
Aparte de ello, las referencias a las canciones e intérpretes populares de la época son recurrentes: uno de los miembros de la collera que demuestra un talento musical lleva por apodo el nombre de un cantante famoso ("Natkinkón”)"11; Cara de Ángel, por su apariencia andrógina es comparado con "María Bonita”, título de una famosa canción que el compositor mexicano Agustín Lara dedicó a su esposa, la actriz María Félix. Asimismo, en un pasaje del cuento "El Príncipe" se menciona la presencia de una radiola en el interior de la "cantina del japonés": "Radiola loca siete colores, siete maracas. [...] Colorete baila solo frente a la radiola. Natkinkón, moreno empedernido, tamborilea en una silla. El Rosquita se abraza Carambola y en dúo acompañan al dúo del disco "Anliyuuu...»"12 (p. 29). Por último, el peluquero Manos Voladoras, quien aparentemente está enamorado de "El Príncipe", utiliza el término "roc” para expresar su admiración por él al enterarse de los eventos en los que ha estado involucrado:

-El Príncipe es el más roc de todos ustedes [...] Tengo muy bien entendido, para que lo sepas [a Corsario] y lo pregones, que ser roc no sólo es usar bluyins y camisa roja; eso es cáscara. Ser roc significa...bueno, por ejemplo, hacer lo que ha hecho el Príncipe (p. 27).

El término hace referencia no solo a un género de música popular que desde la década de los años cincuenta se populariza entre los jóvenes ${ }^{13}$, sino a la actitud rebelde e irreverente de aquellos que preferían ese tipo de música. Así, por ejemplo, en una reseña publicada en 1964 en el diario El Comercio, dedicada a la segunda edición de Los inocentes — significativamente titulada Lima en Rock-, el escritor Sebastián Salazar Bondy afirma:

\footnotetext{
11 Nat King Cole (1919-1965) — cuyo verdadero nombre fue Nathaniel Adams Colesfue un cantante y pianista estadounidense de jazz.

12 Se trata en este caso de la canción "Only you" que popularizara el grupo coral "The Platters” en 1955.

13 “[...] la emergencia de las culturas juveniles está estrechamente asociada al nacimiento del rock \& roll, la primera gran música generacional. A diferencia de otras culturas musicales anteriores (incluso el jazz), lo que distingue al rock es su estrecha integración en el imaginario de la cultura juvenil: los ídolos musicales «son muchachos como tú», de tu misma edad y medio social, con parecidos intereses” (Feixa 1999: 101).
} 
Lo importante es que las historias de Lima en Rock nos cogen y, en algunos momentos, nos sobrecogen. Tenemos la imagen de esa juventud que, además de ser todo lo impulsiva, irrespetuosa y levantisca que es la juventud por sí, enfila su descontento e inadaptación contra cualquier signo del orden que ha sido consagrado como un Orden Sagrado, aún [sic] contra el más insignificante. Lo importante es borrar toda expresión de esa estructura que niega la libertad y niega, por ende, todo futuro (1964: 8).

El rock es en sus orígenes un género musical con el que se identifican los adolescentes de los sectores urbano populares. Aun cuando sería más tarde adoptado por aquellos que pertenecían a la clase media, su versión más primitiva provocaba reacciones adversas entre los sectores más conservadores de las sociedades occidentales ${ }^{14}$. En el cuento "El Príncipe", la censura y el rechazo social que el "rocanrolerismo" genera aparecen representados en un extracto periodístico referido a la captura del protagonista: "Extraoficialmente nos hemos informado de que el joven rocanrolero sigue estudios secundarios en una Unidad Escolar de la Capital. Llamamos la atención de nuestros educadores para que, de una vez por todas, enfrenten con valentía este agudo problema de rocanrolerismo” (p. 30). El texto tematiza la reacción de una sociedad que considera al adolescente rocanrolero como una amenaza para su estabilidad y continuidad. La rebeldía asociada con ese tipo de música exige una mayor dedicación de parte de instituciones de la cultura hegemónica como la escuela para vigilar y reglamentar su conducta. En tal sentido, los contenidos vertidos por los medios de comunicación expresan la preocupación de aquellos sectores dominantes de la sociedad que pretenden modelar la identidad del sujeto juvenil de acuerdo con sus propios intereses.

\footnotetext{
14 "Nuestra civilización occidental se halla amenazada por la invasión vertical de una nueva generación reacia a todo código moral. Los actos de delincuencia juvenil, que tan profusamente se recogen en las páginas de sucesos, no son más que avanzadillas de una era anárquica y primitiva, que se vale del número, del grupo y del anonimato [...] El mal de fondo no reside en las características externas de estos muchachos: su vivir estrafalario, su peinado extravagante, su gusto por la bullanguería. su afición al rock \& roll o al twist, su fervor por el exceso de velocidad y su agrupación en pandillas” (López Riocerezo, citado en Feixa 1999: 42).
} 


\section{CONFORMismo en LOS CACHORROS}

A diferencia de los relatos de Reynoso, situados en el escenario de una zona urbana popular y expresión de una "cultura juvenil obrera" en los términos planteados por Feixa, los protagonistas de Los cachorros se desarrollan en el contexto de la clase media limeña. Como bien se sabe, la figura del adolescente está presente en la obra de Vargas Llosa inicialmente en los cuentos "Los jefes" y "Día Domingo", incluidos en Los jefes ([1959] 2001), así como en la novela La ciudad los perros (1962). En Los cachorros se representa el drama de Pichula Cuéllar ${ }^{15}$, un niño que sufre tempranamente un terrible accidente - una castración — que habrá de conducirlo lentamente a su autodestrucción: la aparente placidez que reina en las primeras páginas del relato, reflejo a su vez de la plenitud en la que viven los niños que asisten al colegio religioso Champagnat ubicado en el corazón del distrito de Miraflores, se ve rápidamente quebrantada por la irrupción de un acontecimiento que arrastra consigo no solo al personaje, sino a su familia y amigos más cercanos.

Si bien la novela traza la trayectoria de vida del protagonista, rasgo que la diferencia del tiempo abarcado en los relatos de Reynoso, el papel que cumple el grupo de amigos es fundamental en la formación de su identidad. Ello se ve reforzado por la importancia que adquieren las técnicas narrativas empleadas en la novela - entre ellas la alternancia de narradores (heterodiegético y homodiegético en tercera persona y primera persona del plural, respectivamente)-, lo cual genera una mayor complicidad y cercanía entre el relato y el lector. Asimismo, en Los cachorros — salvo el caso de Cuéllar, quien no alcanza nunca la adultez dada su muerte prematura-, la adolescencia es representada como un periodo por el que necesariamente han de atravesar aquellos cuyas vidas habrán de desarrollarse por

\footnotetext{
15 "La historia se convirtió en un cuento largo (o novela corta, si se atiende, más que a sus proporciones, a su tensión estructural) que iba a titularse "Pichula Cuéllar", título brutal y provocador para el lector peruano (la palabra "pichula", que designa el sexo masculino, es impronunciable y, por cierto, impublicable), pero que finalmente se llamó, con mayor cordialidad, "Los cachorros" ("Pichula Cuéllar" pasó a ser un discreto subtítulo en la edición original de 1967)” (Oviedo 1970: 25).
} 
los cauces que dicta el orden social. En términos generacionales, pues, no existe en la novela un enfrentamiento abierto con el mundo de los adultos: si bien la actuación de las figuras representativas de la cultura parental - los padres del protagonista o los hermanos encargados de la educación de los niños y adolescentes del colegio Champagnat- puede suscitar algún tipo de crítica ${ }^{16}$, ello no genera un conflicto de intereses entre ambos: implícitamente los jóvenes aceptan el hecho de que cuando tengan la edad de sus padres serán como ellos, lo cual se confirma al final de la novela ${ }^{17}$.

En relación con el género, las relaciones entre sexos cobran protagonismo a partir del final del segundo capítulo:

[...] en esa época, además, de los deportes, ya se interesaban por las chicas. Habíamos comenzado a hacer bromas, en las clases, oye, ayer lo vi a Pirulo Martínez con su enamorada, en los recreos, se paseaban de la mano por el Malecón y de repente ipum, un chupete!, y a las salidas, ¿en la boca?, sí y se habían demorado un montón de rato besándose (p. 39).

A diferencia de los adolescentes de Los inocentes, en la novela de Vargas Llosa, con la única excepción del protagonista, estos no atraviesan los mismos dilemas existenciales: la necesidad de manifestar la virilidad a través de la violencia o la consumación de la relación sexual está ausente. Más bien, canalizan su interés por atraer a las muchachas a través del baile que opera como una forma de sublimación del deseo sexual ${ }^{18}$, así como buscan proyectar una imagen "adulta" de sí mismos mediante el consumo de cigarrillos o alcohol:

16 La más evidente de estas “faltas” podría ser el hecho de que, una vez producido el evento central de la novela, la castración de Cuéllar, sus padres comienzan a sobreproteger a su hijo al punto de convertirlo en alguien incapaz de relacionarse con el mundo que lo rodea.

17 "Eran hombres hechos y derechos ya y teníamos todos mujer, carro, hijos que estudiaban en el Champagnat, la Inmaculada o el Santa María, y se estaban construyendo una casita para el verano en Ancón, Santa Rosa o las playas del Sur, y comenzábamos a engordar y a tener canas, barriguitas, cuerpos blandos, a usar anteojos para leer, a sentir malestares después de comer y de beber y aparecían ya en sus pieles algunas pequitas, ciertas arruguitas” (p. 105).

18 En Los inocentes, solo hay una referencia al baile al final del cuento "Colorete". 
“[...] ¿qué pasaba en el salón?, ¿qué hacían las chicas con esos agrandados, qué envidia, que ya sabían bailar? Hasta que un día se decidieron a aprender ellos también y entonces nos pasábamos sábados, domingos íntegros, bailando entre hombres [...]” (pp. 41-42). Así, se instruyen acerca de los modos de bailar diferentes géneros musicales — huarachas, mambos, boleros y valses (p. 42) antes de declararse a las muchachas (p. 51). Cuéllar, en cambio, no logra satisfacer los requerimientos del grupo social en relación con el sexo opuesto; sus “proezas” están más bien destinadas a evitar ser feminizado por sus pares (p. 51) y exhibir los rasgos de una masculinidad exacerbada desarrollándose físicamente (p. 48), todo ello como respuesta a la pérdida de sus genitales ${ }^{19}$. Las incursiones grupales al prostíbulo tampoco redundan en su beneficio, pues incluso allí es víctima de burlas:

[...] terminábamos generalmente en la Avenida Grau, donde Nanette. Ya llegaron los miraflorinos, porque ahí los conocían, hola Pichulita, por sus nombres y por sus apodos, ¿cómo estás? Y las polillas se morían y ellos de risa: estaba bien. Cuéllar se calentaba y a veces las reñía y se iba dando un portazo, no vuelvo más, pero otras se reía y les seguía la cuerda [...] (p. 91).

La representación de las muchachas en la novela, por otra parte, reproduce los estereotipos y convenciones de una sociedad patriarcal en la cual las mujeres deben satisfacer las exigencias de los hombres: "Y Lalo: había que ayudarlo [a Cuéllar], lo decía en serio, le conseguiríamos una hembrita aunque fuera feíta [...]” (p. 54). Ello se evidencia incluso en los diálogos con sus pares o con el propio Cuéllar:

\footnotetext{
19 Sin embargo, siempre está latente la posibilidad de la homosexualidad de Cuéllar al relacionarse con muchachos menores: "Les enseñaba a manejar el Volvo, se lucía ante ellos dando curvas en dos ruedas en el Malecón y los llevaba al Estadio, al cachascán, a los toros, a las carreras, al Bowling, al box. Ya está decíamos, era fatal: maricón. Y también: qué le quedaba, se comprendía, se le disculpaba pero, hermano, resulta cada día más difícil juntarse con él [...]” (p. 98).
} 
Pero él no quería tener enamorada y ponía cara de forajido, prefiero mi libertad, y de conquistador, solterito estaba mejor. Tu libertad para qué, decía la China, ¿para hacer barbaridades?, y Chabuca ¿para irse de plancito?, y Pusy ¿con huachafitas?, y él cara de misterioso [...] Lo que pasan es que no te gustan las chicas decentes, decían ellas, y él como amigas claro que sí, y ellas sólo las cholas, las medio pelo, las bandidas [...] (pp. 55-56).

A juicio de las adolescentes, aquellas mujeres que no forman parte de su entorno social ni satisfacen requisitos de estatus o raza no merecen ser consideradas por sus pares masculinos, pero al evidenciar esta posición dejan en claro lo que entienden por "feminidad”, es decir, confirman que "[e]xisten fundamentalmente por y para la mirada de los demás, es decir, en cuanto que objetos acogedores, atractivos, disponibles" (Bourdieu 1998: 50). Por otro lado, las referencias de Cuéllar a su soltería y libertad inciden en la idea de que los hombres, a diferencia de las mujeres, disponen de una mayor libertad para relacionarse con estas; sin embargo, cuando Cuéllar conoce a Teresita Arrarte, se abre ante él no solo la posibilidad de una pareja que cumple con los requisitos estipulados por su extracción social, sino la de recuperar su virilidad a través de una operación en Estados Unidos e incorporarse así al orden social:

Anunció que iba a estudiar: el año próximo entraría a la Católica y ella disforzada qué bien, ¿qué carrera iba a seguir? Y le metía por los ojos sus manitas blancas, seguiría abogacía, sus deditos gordos y sus uñas largas, ¿abogacía? ¡uy, qué feo!, pintadas color natural, entristeciéndose $[\ldots]$ manitas, ojos, pestañas [...] boquita, ¡uy, qué lindo! $[\ldots]$ (p. 75).

La decisión de Cuéllar produce en Teresita las reacciones propias de una niña (“¡uy, qué feo!”; “uy, qué lindo!”) que es, además, objetivada, dado que lo más representativo en ella son sus "manitas”, “deditos”, “uñas largas”, “ojos” y “pestañas”. Por último, cuando finalmente acepta a Cachito como enamorado, los amigos de Cuéllar la envilecen - “[...] qué coqueta, qué desgraciada, qué perrada le hizo” (p. 84)—. Como sucede en los relatos 
de Reynoso, la reacción de los adolescentes hace evidente el hecho de que aquellas mujeres que no satisfacen los requerimientos de los hombres - pasividad, fidelidad, entre otros - no merecen ser respetadas. En este caso, sin embargo, asistimos a una doble victimización del protagonista, pues Cuéllar padece de antemano una condición de inferioridad por su castración. Así, desde el punto de vista de sus amigos, la "vileza" de Teresita también residiría en no haberse compadecido de él, es decir, no haber respondido al modelo de mujer protectora y maternal que el orden social estipula.

Los territorios en los cuales los adolescentes construyen sus identidades principalmente son los del ocio: la calle, el billar, el cine, el club social, la playa, entre otros. En ese sentido, a lo largo de la novela se identifica una serie de topónimos que incluye no solo los nombres de calles y avenidas, sino marcas, instituciones, tiendas y establecimientos de todo tipo. Si durante la infancia el escenario de las aventuras se limita a los recorridos de los niños por espacios aledaños al colegio - la avenida Diagonal, la "bodeguita de la esquina de D'Onofrio", la calle Porta o el club "Terrazas"-, conforme se van adentrando en la adolescencia, a esta incipiente topografía se agregan nombres de lugares signados por la búsqueda incesante del placer: las tiendas de discos, los restaurantes, el "Billar de la Alameda Ricardo Palma", los bares, la playa "La Herradura", los clubes privados, los cabarets, clubes nocturnos y cantinas. A través de esta extensa cadena, se constata el crecimiento de la urbe y la diversificación de la oferta para la clase social de los protagonistas. En tal sentido, al menos para estos, la ciudad se presenta como un espacio liberal y hedonista; en ella, el mundo nocturno del espectáculo y la farándula se ha convertido en una categoría más en la circulación de bienes y mercancías. Evidentemente, ello también expresa la apropiación de un espacio/tiempo a disposición de los jóvenes en el que, apartados de las obligaciones y restricciones impuestas por la cultura parental, se les permite gozar de mayores libertades. En tal sentido, el sexo, el alcohol e, incluso, el vértigo de la velocidad son vehículos de rápido acceso en la búsqueda del placer efímero. 
En el caso del protagonista, la presencia de estos escenarios le permite colmar el vacío de su existencia. Estos representan una suerte de reemplazo de la pérdida de la posibilidad de una vida sexual "normalizada", pero el precio a pagar por ello es muy alto: la vía elegida, que comporta el riesgo, el desprestigio social y la marginación de su propia clase, lo conduce a su propia destrucción. Por otra parte, hay implícita una condena de la amoralidad del protagonista filtrada a través de la voz del narrador, quien por momentos parece identificarse con el punto de vista de sus amigos o, en todo caso, de la sociedad:

Su carro andaba siempre repleto de rocanroleros de trece, catorce, quince años y, los domingos, se aparecía en el "Waikiki" (hazme socio, papá, la tabla hawaiana era el mejor deporte para no engordar y él también podría ir, cuando hiciera sol, a almorzar, con la vieja, junto al mar) con pandillas de criaturas, mírenlo, mírenlo, ahí está, qué ricura, y qué bien acompañado se venía, qué frescura: uno por uno los subía a su tabla hawaiana y se metía con ellos más allá de la reventazón. Les enseñaba a manejar el Volvo, se lucía ante ellos dando curvas en dos ruedas en el Malecón y los llevaba al Estadio, al cachascán, a los toros, a las carreras, al Bowling, al box. Ya está decíamos, era fatal: maricón. Y también: qué le quedaba, se comprendía, se le disculpaba pero, hermano, resulta cada día más difícil juntarse con él (p. 98).

El uso del imperativo expresa el rechazo de aquellos que censuran estilo de vida del protagonista, con lo cual se metaforizan en la narración las maledicencias de la cultura hegemónica que impone una férrea vigilancia sobre quienes atentan contra sus hábitos y estilo de vida. Colocada en el último capítulo de la novela, la insinuación de la homosexualidad de Cuéllar es una clara señal de su "decadencia moral" y, en cierta medida, hace "comprensible" para un lector prejuicioso su triste final: su muerte violenta es el castigo que merecen aquellos que se alejan de los modelos pautados por una sociedad conservadora e intolerante. Sin embargo, un lector no identificado con esta mirada censora podría compadecerse del personaje: imposibilitado por la emasculación a seguir el camino designado para los de 
su clase - tener una pareja, casarse y formar una familia - Cuéllar es condenado a ser eternamente un adolescente, es decir, un ser incompleto sumido en el dolor de "no poder ser", “incapaz" en un doble sentido de la palabra, pues para él ni siquiera existe la posibilidad de convertirse en alguien distinto a quien es. En tal sentido, la pregunta acerca de la naturaleza del personaje —¿Quién es Cuéllar? - no encuentra una respuesta. Su tragedia consiste en nunca llegar a saber "quién es" o "quién podría haber sido" si es que al menos hubiera tenido esa posibilidad: para él, la simple posibilidad de “ser” deja de existir desde el momento en que es despojado de su virilidad.

Queda, por último, hacer una referencia a las imágenes culturales presentes en la novela. Los indicios de la presión que ejerce la sociedad de consumo sobre los protagonistas se manifiestan principalmente en la figura de Cuéllar. Desde el momento de su emasculación, los padres del protagonista intentan paliar la gravedad del accidente poniendo a su alcance toda clase de compensaciones materiales; así, es el primero del grupo en tener un automóvil propio (p. 55), símbolo de status entre sus pares, pero reemplazo subliminal de su miembro viril. La facilidad con la que dispone de estos medios, sin embargo, no le impide percibir la vaciedad y el sinsentido de su vida y la de sus pares:

[...] se había entristecido un poco nada más, y ellos por qué si la vida era de mamey, compadre, y él de un montón de cosas, y Mañuco de qué por ejemplo, y él de que los hombres ofendieran tanto a Dios por ejemplo, y Lalo ¿de que qué dice?, y Choto ¿quería decir de que pecaran tanto?, y él sí, por ejemplo, ¿qué pelotas, no?, sí, y también de lo que la vida era tan aguada. Y Chingolo qué iba a ser aguada, hombre, era de mamey, y él porque uno se pasaba el tiempo trabajando, o chupando, o jaraneando, todos los días lo mismo y de repente envejecía y se moría ¿qué cojudo, no?, sí. ¿Eso había estado pensando donde Nanette?, ¿eso delante de las polillas?, sí, ¿de eso había llorado?, sí, también de pena por la gente pobre, por los ciegos, los cojos, por esos mendigos que iban pidiendo limosna en el jirón de la Unión, y por los canillitas que iban vendiendo " $\mathrm{La}$ Crónica” ¿qué tonto, no? Y por esos chibolitos que te lustran los zapatos en la Plaza San Martín ¿qué bobo, no? (p. 95). 
Parcialmente situado al margen de las convenciones de su grupo social, Cuéllar percibe las contradicciones de la vida burguesa; así, su condición lo faculta para colocarse, al menos sentimentalmente, en el lugar de los "otros": los desvalidos, es decir, los ciegos, cojos, mendigos, lustrabotas y la larga secuela de sujetos marginados por la sociedad. Durante los breves lapsos en los que se sincera consigo mismo y con sus amigos — producto del estado semiinconsciente en que se encuentra por influencia del alcohol- vislumbra el tedio y la monotonía de la vida burguesa, pero es incapaz de formular un discurso coherente y lúcido al respecto; la vejez y la muerte son para él —como lo son para un adolescente- realidades lejanas e incomprensibles, de ahí a que se limite a dar cuenta de la pobreza, el hambre y la fealdad del mundo que lo rodea. Ello, finalmente, lo lleva a descalificar sus propios juicios por absurdos y "bobos"; sin embargo, su incapacidad y la de sus amigos para trascender lo banal y anodino, y comprender en qué consisten las contradicciones de la realidad hace explícita la posición crítica del narrador frente a sus personajes.

Con respecto a los demás factores que contribuyen a la construcción de la identidad de los personajes adolescentes —el lenguaje verbal, la música, la moda-, también se perciben diferencias significativas; en el primer caso, los rasgos de oralidad que dan cuenta de los hábitos lingüísticos de los personajes no se limitan a las expresiones, giros y usos propios del grupo de muchachos, sino que incluyen también a las adolescentes. Así, un tejido polifónico brinda información acerca de las reacciones y juicios que suscita la conducta de Cuéllar. No se trata en este caso de un sociolecto que traza un lindero entre el habla de los adultos y la de los jóvenes para destacar el arrojo, astucia o complicidad de los protagonistas: "Ya está, decía Fina, le llegó su hora, se enamoró. Y Chabuca qué templado estaba, la miraba a Teresita y se le caía la baba, y ellos en las noches, alrededor de la mesa de billar, mientras lo esperábamos ¿le caerá?, Choto ¿̇e atreverá?, y Chingolo ¿'Tere sabrá?” (p.70). Si se presta atención al lenguaje del grupo, se percibe una cierta comunión en los usos y formas lingüísticas de ambos sexos, lo cual, sin 
embargo, no implica una nivelación en cuanto a las prerrogativas que goza cada uno. La música bailable, por otra parte, como ya se mencionó anteriormente, cobra importancia como parte del cortejo de los muchachos a las chicas, así como la breve referencia al "Rey del mambo" Pérez Prado que causó furor entre los jóvenes a su paso por Lima ${ }^{20}$. Un caso distinto es el del bolero "Quizás, quizás, quizás” cuya letra sirve de comentario a las muchachas sobre la indecisión de Cuéllar²1: "Pero las semanas corrían y nosotros cuándo, Pichulita, y él, no se decidía, le caería mañana, palabra sufriendo como nunca lo vieron antes ni después, y las chicas «estás perdiendo el tiempo, pensando, pensando» cantándole el bolero «Quizás, quizás, quizás»” (p. 82). Estas referencias, sin embargo, no establecen una barrera entre el gusto musical de los adultos y adolescentes; incluso la mención de los "rocanroleros de trece, catorce, quince años" que frecuenta un Cuéllar mayor revelaría el hecho de que el "Rock” no es un género musical con el cual se sienten identificados los y las adolescentes de la novela, lo cual, una vez más, es una señal de que sus identidades se construyen con materiales muy distintos a los de los protagonistas de los relatos de Reynoso. Finalmente, sí podría establecerse un paralelismo con respecto a la moda sobre la base de una de las pocas menciones que aparecen en la novela vinculada con la vestimenta de Cuéllar: “[...] pero en el día vagabundeaba de un barrio de Miraflores a otro y se lo veía en las esquinas, vestido como James Dean (blue jeans ajustados, camisita de colores abierta desde el pescuezo hasta el ombligo, en el pecho una cadenita de oro bailando y enredándose entre los vellitos, mocasines blancos) [...]” (p. 98). Paradójicamente, la apariencia de Cuéllar en el pasaje es el fiel reflejo de cómo Cara de Ángel hubiera deseado verse en la vitrina de la tienda del Jirón de la Unión al inicio del relato de Reynoso, de no ser por las inquebrantables barreras y prejuicios que lo marginan de la sociedad limeña.

\footnotetext{
20 El músico cubano Dámaso Pérez Prado — consignado como el inventor del “mambo"- llegó a Lima con su orquesta en marzo de 1951.

21 Canción popular escrita en 1947 por el compositor cubano Osvaldo Farrés.
} 


\section{Conclusiones}

Como se ha podido demostrar a lo largo de este trabajo, los relatos incluidos en Los inocentes de Oswaldo Reynoso y la novela Los cachorros de Mario Vargas Llosa plantean la existencia de dos tipos de culturas juveniles que se distinguen en relación a los factores y materiales con los que los adolescentes construyen sus identidades. Si, en el primer caso, se hace evidente la rebeldía y el abierto enfrentamiento a la cultura hegemónica y parental de los integrantes de la collera con base en su extracción de clase, generación, género, territorialización e imágenes culturales, los protagonistas de la novela no expresan a través de esos materiales su inconformismo. En tal sentido, puede afirmarse que se trata de dos expresiones muy disímiles situadas ambas en el contexto de emergencia de las llamadas culturas juveniles a partir de la década de los años cincuenta y que se dan lugar en el marco de una ciudad en pleno proceso de modernización.

\section{REFERENCIAS BIBLIOGRÁFICAS}

BOURDIEU, Pierre

1998 La dominación masculina. Trad., J. Jordá. Barcelona: Anagrama.

Congrains Martín, Enrique

1957 No una, sino muchas muertes. Montevideo: Editorial Alfa, Moncloa Editores.

FeIXA, Carles

1999

De jóvenes, bandas y tribus. Antropología de la juventud. Barcelona: Ariel.

GÜıch, José y Alejandro SusTi

2007 Ciudades ocultas: Lima en el cuento peruano moderno. Lima: Fondo Editorial Universidad de Lima.

Marqués, Josep-Vicent

1997 "Varón y patriarcado". En Masculinidad/es. Poder y crisis. Eds., T. Valdés y J. Olavarría. Santiago de Chile: Isis Internacional. 
Oviedo, José Miguel

1970 "Los cachorros: Fragmento de una exploración total”. Revista Iberoamericana. XXXVI, 70, 25-38.

Reynoso, Oswaldo

[1961] 2011 Los inocentes. Relatos de collera. Lima: Estruendomudo.

Ribeyro, Julio Ramón

[1960] 2001 Crónica de San Gabriel. Lima: Peisa.

RosZAK, Theodore

1981 El nacimiento de una contracultura. Reflexiones sobre la sociedad tecnocrática y su oposición juvenil. Barcelona: Kairós.

SAlAZAR Bondy, Sebastián

1964 "La sociedad «rocanrolera»". El Comercio. Suplemento Dominical. Lima, 22 de marzo, p. 8.

VARgas Llosa, Mario

[1959] 2001 Los jefes/Los cachorros. Lima: Peisa.

VARgas Llosa, Mario

1962 La ciudad y los perros. Barcelona: Seix Barral.

Vargas Llosa, Mario, Xavier Miserachs

1967 Los cachorros. Barcelona: Lumen.

Recepción: 27/01/2020

Aceptación: 24/08/2020 